\title{
A Comparative Study of Intravenous Nitroglycerin With or Without Intravenous Lignocaine for Attenuation of Stress Responses to Endotracheal Intubation
}

\author{
Regmi NK', Singh $\mathrm{G}^{2}$
}

\begin{abstract}
Background: Laryngoscopy and tracheal intubation lead to stress response which is characterized by transient rise in blood pressure and heart rate. This response is tolerated well in normal individuals but can lead to significant morbidity and mortality in patients with cardiovascular and cerebrovascular diseases. Search for the better drugs to suppress these responses is going on through decades. Aim of Study: To compare the effects of IV nitroglycerin alone and in combination with IV lignocaine, on attenuation of stress response to endotracheal intubation. Material and Methods: This is a randomized, double blind study conducted in 60 patients admitted for operation at NGMCTH, between June 2018 to November 2018. Patients were of 16- 60 years age groups and belonging to ASA group I and II. Patients were divided into two groups: Group I IV Nitroglycerin $500 \mathrm{mcg}+\mathrm{NS} 3 \mathrm{ml}$. ( $\mathrm{n}=30$ ) and Group II IV Nitroglycerin $500 \mathrm{mcg}+$ IV Lignocaine $63 \mathrm{mg}(\mathrm{n}=30)$. Systolic Blood Pressure (SBP), Diastolic Blood Pressure (DBP), Mean Arterial Pressure (MAP) and Heart rate (HR) were measured and Rate Pressure Product (RPP) calculated. Results: Baseline values were comparable in both groups. Post Intubation, there was significant decrease in SBP at 0,1,3 and 5 minutes while DBP and MAP significantly decreased at 1, 3 and 5 minutes, in both groups. Significant tachycardia was noted in both groups at 0,1and 3 minutes, and RPP remained unchanged in both groups. Conclusion: Nitroglycerin significantly decreases blood pressure, prevents rise in RPP but does not attenuate heart rate after endotracheal intubation. There is no benefit of adding IV lignocaine to IV nitroglycerin for attenuation of stress response to endotracheal intubation.
\end{abstract}

Key Words: Nitroglycerin, lignocaine, intubation, stress response.

\section{INTRODUCTION:}

Laryngoscopy and endotracheal intubation leads to an average increase in blood pressure by $40-50 \%$ and heart rate by $20 \%{ }^{1}$. Although, these hemodynamic changes after intubation cause no significant morbidity in healthy individuals, these can lead to hypertensive crisis, pulmonary edema, cardiac dysrhythmias, myocardial ischemia, and cerebral hemorrhage in the presence of cardiovascular and cerebrovascular disease $\mathrm{e}^{2,3}$.

A wide variety of pharmacological agents are used to attenuate the hemodynamic responses to endotracheal intubation, like lignocaine, fentanyl, alfentanil, remifentanil, nifedipine, betablockers, gabapentin, nitroglycerin, magnesium sulfate, verapamil, nicardipine, diltiazem with varying results ${ }^{4}$. Among these drugs, the advantage of using nitroglycerin (NTG) during intubation is that, while a desirable and transient hypotension is achieved, cardiac output is not likely to decrease ${ }^{5}$. In addition, it has cardioprotective effect ${ }^{6}$. Most of the studies have found that NTG successfully prevent increase in BP, although it does not attenuate heart rate ${ }^{2,7,8}$.

1. Dr. Nabin Kumar Regmi

2. Dr. Grisuna Singh

Address for correspondence:

Dr. Nabin Kumar Regmi

Department of Anaesthesia

Nepalgunj Medical College and Teaching Hospital

Nepalgunj, Banke, Nepal

Email:nabinkums@gmail.com
Lignocaine is class IB antiarrhythmic drugs commonly used for attenuation of haemodynamic response to laryngoscopy and intubation as it is devoid of cardiovascular side effects except when used in larger doses. ${ }^{9}$ Studies have shown that it significantly reduces heart rate post intubation ${ }^{10,11}$. On search of ideal drugs and technique to blunt these effects, some anesthesiologists are even combining two drugs based on their pharmacological action ${ }^{11,12}$. In this study we combined these cardioprotective and antiarrhythmic drugs.

\section{MATERIALAND METHODS:}

This is a prospective, randomized, double blind study. This study was conducted from June 2018 to November 2018 in the Department of Anaesthesiology, Nepalgunj Medical College, after taking approval from Institution Review Committee. 60 patients were enrolled for the study. Patient of age 16 to 60 years, ASA physical status I and II, scheduled for surgery under general anaesthesia and giving consents for the study were taken as study samples. Patients with hypertension, ASA grade III and IV, patient suspected of difficult intubation and endotracheal intubation taking more than 30 seconds were excluded from the study.

All patients were admitted to the hospital at least a day before surgery and routine pre anesthetic checkup followed by premedication with diazepam $5 \mathrm{mg}$ and pantoprazole $40 \mathrm{mg}$ was done. On arrival in operation room pulse-oximeter, blood pressure, electrocardiogram, were applied and the patients' SBP, DBP, MAP, HR and RPP were measured and taken as baseline values. All patients received $0.2 \mathrm{mg}$ glycopyrrolate and 
$2 \mathrm{mg}$ midazolam before induction. Fentanyl, Propofol and vecuronium were used for $G A$.

Patients were randomly divided to 2 groups in a double blind manner.

Group I: IV Nitroglycerin $500 \mathrm{mcg}+3 \mathrm{ml} \mathrm{NS}$

Group II: IV Nitroglycerin $500 \mathrm{mcg}+63 \mathrm{mg}$ Lignocaine (Volume= $3 \mathrm{ml})$

Study drugs were given as bolus dose during induction of anaesthesia. Time just after intubation was taken as 0 minute.

\section{Statistical Analysis:}

Data was analyzed using SPSS 20. Independent sample t test, for comparison of variables among the groups and one sample $t$ test, for comparison of variable within the groups were used. $P$ value less than 0.05 was considered significant.

\section{RESULTS}

The mean age of group I and group II were, 34.37 and 33.03 respectively. The difference was statistically insignificant. There was no any significant difference on baseline variables (SBP, DBP, MAP, HR, RPP), between the groups.

\begin{tabular}{|l|c|c|c|c|c|c|c|c|}
\hline & \multicolumn{3}{|c|}{ Group I } & \multicolumn{3}{c|}{ Group II } \\
\cline { 2 - 9 } & $\mathbf{N}$ & Mean & $\begin{array}{c}\text { Std. } \\
\text { Deviation }\end{array}$ & P Value & N & Mean & $\begin{array}{c}\text { Std. } \\
\text { Deviation }\end{array}$ & value \\
\hline SBP Baseline & 30 & 125 & 11.955 & 30 & 30 & 124 & 11.702 & .828 \\
\hline DBP Baseline & 30 & 75.43 & 8.997 & 30 & 30 & 78.63 & 8.584 & .164 \\
\hline MAP Baseline & 30 & 90 & 9.884 & 30 & 30 & 92.17 & 9.735 & .395 \\
\hline HR Baseline & 30 & 90.97 & 16.113 & 30 & 30 & 91.13 & 14.311 & .966 \\
\hline RPP Baseline & 30 & 11.423 & 2.510 & 30 & 30 & 11.320 & 1.989 & .861 \\
\hline
\end{tabular}

Table I: Comparison of Baseline Variables between the groups

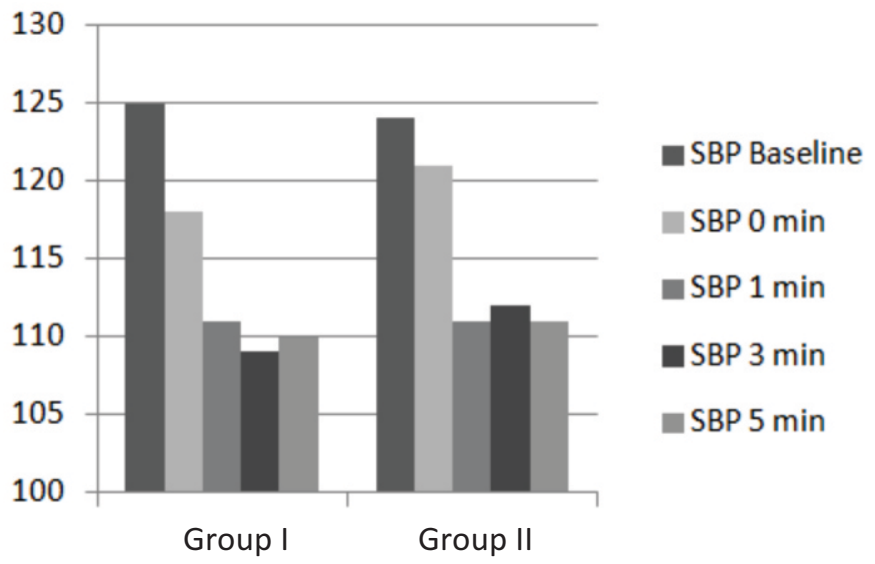

Figure 1: Comparison of SBP values

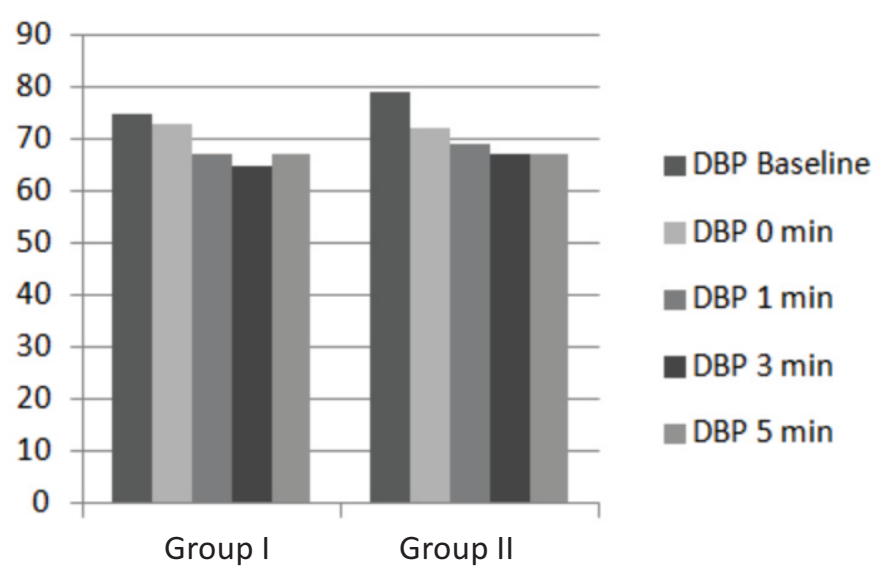

Figure 2: Comparison of DBP values

In both groups there was significant decrease in SBP, DBP and MAP from their baselines. DBP 0 min and MAP 0 min were exception in both the groups, as the decrease was not statistically significant. The highest decrease was observed at 3 minutes from intubation.

\begin{tabular}{|c|c|c|c|c|c|c|c|c|}
\hline & \multicolumn{4}{|c|}{ Group I } & \multicolumn{4}{|c|}{ Group II } \\
\hline & $\mathbf{N}$ & Mean & $\begin{array}{c}\text { Std. } \\
\text { Deviation }\end{array}$ & P Value & $\mathbf{N}$ & Mean & $\begin{array}{c}\text { Std. } \\
\text { Deviation }\end{array}$ & P value \\
\hline MAP Baseline & 30 & 90.00 & 9.844 & 1.000 & 30 & 92.17 & 9.735 & .999 \\
\hline MAP $0 \mathrm{~min}$ & 30 & 86.50 & 13.274 & .159 & 30 & 85.53 & 20.551 & .087 \\
\hline MAP $1 \mathrm{~min}$ & 30 & 80.73 & 13.928 & .001 & 30 & 81.00 & 18.078 & .002 \\
\hline MAP $3 \mathrm{~min}$ & 30 & 78.63 & 13.145 & .000 & 30 & 80.93 & 15.763 & .001 \\
\hline MAP $5 \mathrm{~min}$ & 30 & 79.77 & 16.012 & .002 & 30 & 79.57 & 16.895 & .000 \\
\hline
\end{tabular}

Table II: Comparison of MAP of two groups from their baseline values. 
Regmi et al.: A Comparative Study of Intravenous Nitroglycerin With or Without Intravenous Lignocaine for Attenuation of Stress Responses to Endotracheal Intubation

\begin{tabular}{|l|c|c|c|c|c|c|c|c|}
\hline & \multicolumn{3}{|c|}{ Group I } & \multicolumn{3}{c|}{ Group II } \\
\cline { 2 - 9 } & $\mathbf{N}$ & Mean & $\begin{array}{c}\text { Std. } \\
\text { Deviation }\end{array}$ & P Value & $\mathbf{N}$ & Mean & $\begin{array}{c}\text { Std. } \\
\text { Deviation }\end{array}$ & P value \\
\hline HR Baseline & 30 & 90.97 & 16.113 & .999 & 30 & 91.13 & 14.311 & .999 \\
\hline HR 0 min & 30 & 100.17 & 15.530 & .003 & 30 & 103.33 & 15.191 & .000 \\
\hline HR 1 min & 30 & 99.77 & 16.128 & .006 & 30 & 101.77 & 16.600 & .001 \\
\hline HR 3 min & 30 & 98.00 & 14.802 & .014 & 30 & 98.67 & 14.269 & .007 \\
\hline HR 5 min & 30 & 94.87 & 16.404 & .203 & 30 & 95.57 & 16.685 & .156 \\
\hline
\end{tabular}

Table III: Comparison of HR of two groups from their baseline values.

The pattern of change in heart rate was similar in both groups. Heart rate significantly increased just after intubation in both groups and gradually decreased. It reached to statistically insignificant level only on $5 \mathrm{~min}$.

Group I

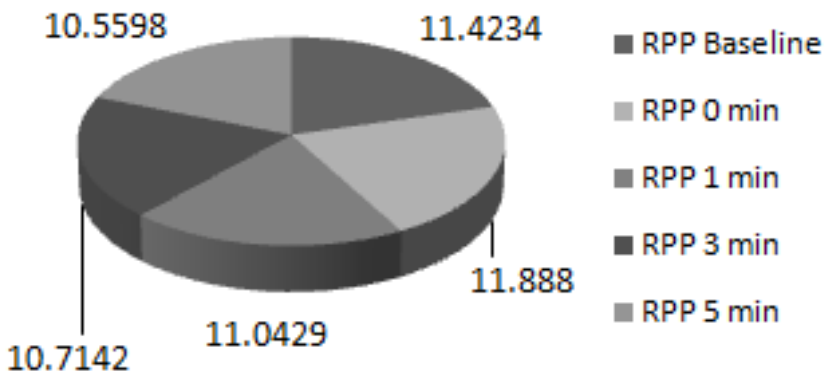

Fig III: Comparison of RPP - group I

There were no statistical significant changes in RPP from their baseline values, among both groups.

\section{DISCUSSION:}

The circulatory response to laryngeal and tracheal stimulation following laryngoscopy and intubation was documented by Reid and Brace in 1940 and by King et al in $1951^{13,14}$. The response to laryngoscopy and intubation is a sympathetic reflex that is provoked by stimulation of the oro-laryngopharyn $x^{15}$.

Dexmedetomidine although have good result for attenuation of intubation response, side effects like bradycardia and hypotension, necessitating need for pharmacological rescue therapy are limitations to its us $\mathrm{e}^{16}$. Short acting opioids appear to have a reliable and constant effect but they may contribute to truncal rigidity and prolong recovery time from general anaesthesia in addition to respiratory depression. Excessive negative chronotopic and inotropic action of the $\beta$-receptor blockers may reduce coronary perfusion and precipitate heart failure in susceptible patients ${ }^{17}$. Vasodilators like intravenous NTG produce reduction in blood pressure but they do not blunt rise in heart rate ${ }^{18}$. So, no single drugs can be concluded as ideal drugs for blunting intubation response. This is why in this chose to combine IV lignocaine with IV NTG and compare the response with response of NTG alone.

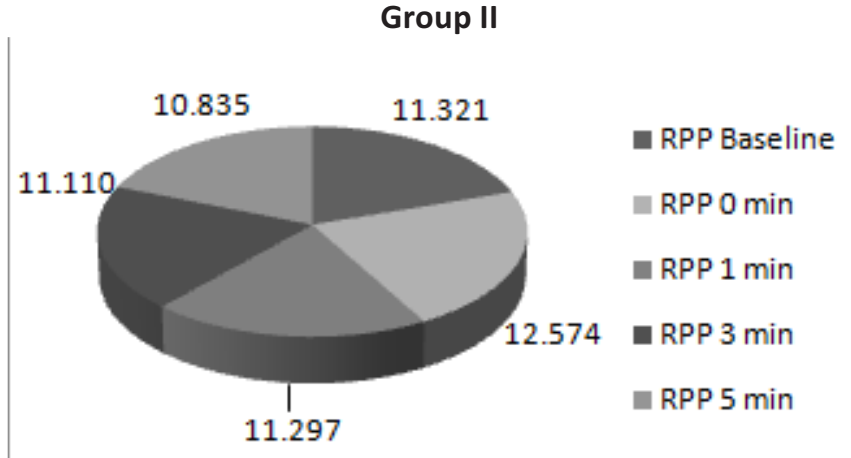

Fig IV: Comparison of RPP - group II

Nitroglycerine is an organic nitrate that acts principally on venous capacitance vessels and large coronary arteries to produce peripheral pooling of blood and decrease cardiac ventricular wall tension ${ }^{19}$. Thus NTG may increase the coronary blood flow and oxygen delivery to the myocardium ${ }^{5}$. NTG had been administered intranasally, or parenterally as a bolus or infusion to attenuate hemodynamic responses during laryngoscopy ${ }^{4}$.

Lignocaine is an aminoethylamide and prototype of amide local anesthetic group ${ }^{20}$. In 1961, Bromage showed that use of intravenous (IV) lignocaine blunted pressure response to intubation $^{21}$. Intravenous lidocaine has been popular probably because of its theoretical advantages of suppressing cough reflex, preventing increases in intracranial pressure, attenuating circulatory responses, and its antiarrhythmic properties ${ }^{22}$.

In our study, demographic profile and baseline hemodynamic parameters i.e., SBP, DBP, MAP, HR and RPP were compared among both groups. Individual hemodynamic parameters in each group were compared with their baseline values. When compared to the baseline values, just after intubation ( $0 \mathrm{~min}$ ), there was significant reduction in SBP, but no significant changes in DBP and MAP in both groups. In 1, 3 and 5 minutes 
there was significant reduction of blood pressure in both groups. At 5 minutes 20\% ( $n=6)$ individuals in Group I and 23\% $(n=7)$ individuals in Group II had hyptension. The hypotension was managed with fast IV fluids and decreasing isoflurane, whereas 1 individuals from each group required $6 \mathrm{mg}$ IV mephentermine. Kumar $\mathrm{N}$ et al in their study found lower increase in SBP, DBP and MAP following administration of 2 $\mathrm{mcg} / \mathrm{kg} \mathrm{NTG}{ }^{23}$ but in our case hypotension have been associated because of higher drug dose, $500 \mathrm{mcg}$ for all individuals.

In both groups, the heart rate was significantly greater at 0 , 1 and 3 minutes. It settled down to the baseline level at $5 \mathrm{~min}$. Similar to this study, Kumari I et al in her study observed that NTG does not attenuate the rise in $\mathrm{HR}^{4}$. Previous studies have also documented that NTG does not attenuate the rise in HR after intubation which can be attributed to reflex tachycardia produced by vasodilation ${ }^{5,24}$.

There was no significant change in RPP from their baselines, in both groups.

This study showed that adding lignocaine had no extra effect than NTG alone. This is consistant with studies done by Vandenberg AA, Sawa D and Honjol NM. ${ }^{7}$ Padmawar S and Patil $M$ also showed that IV lignocaine did not have any effect on the hemodynamic changes following intubation ${ }^{25}$.

\section{CONCLUSION}

Nitroglycerin significantly decreases blood pressure, prevents rise in RPP but does not attenuate heart rate after endotracheal intubation. There is no benefit of adding IV lignocaine to IV nitroglycerin for attenuation of stress response to endotracheal intubation.

\section{REFERENCES}

1. Bruder N, Ortega D, Granthil C. Consequences and prevention methods of hemodynamic changes during laryngoscopy and intratracheal intubation. Ann Fr Anesth Reanim 1992; 11:57-71.

2. Gupta P, Panda B, Verma R et al. Attenuation of Haemodynamic Responses to Laryngoscopy \& Intubation following Nitroglycerin and Esmolol infusion. The Internet Journal of Anesthesiology. 2009 Vol 22 Number 2.

3. Braunwald E. Control of myocardial oxygen consumption physiological and clinical consideration. Am. J. Cardiol. 1971;27: 416-432.

4. Kumari I, Naithani U, Dadheech VK, Pradeep DS, Meena K, Verma D. Attenuation of pressor response following intubation: Efficacy of nitro-glycerine lingual spray. J Anaesthesiol Clin Pharmacol 2016;32:69-73.

5. Mikawa K, Hasegawa M, Suzuki T, Maekawa N, Kaetsu H, Goto R, et al. Attenuation of hypertensive response to tracheal intubation with nitroglycerin. J Clin Anesth 1992;4:367-71.

6. Tanoue Y1, Morita S, Ochiai Y, Haraguchi N, Tominaga R, Kawachi $\mathrm{Y}$, Yasui $\mathrm{H}$. Nitroglycerin as a nitric oxide donor accelerates lipid peroxidation but preserves ventricular function in a canine model of orthotopic heart transplantation. J Thorac Cardiovasc Surg. 1999 Sep;118(3):547-56.
7. Vandenberg AA, Sawa D, Honjol NM. Attenuation of the haemodynamic responses to noxious stimuli in patients undergoing cataract surgery. A comparison of magnesium sulphate, esmolol, lignocaine, nitroglycerine and placebo given i.v. with induction of anaesthesia. Eur J Anaesthesiol; 1997, Mar;14(2):134-47.

8. Perezpena JM, Olmedela AL, Jimeno FC, Navia RJ. Effect of an intravenous nitroglycerine bolus on the hemodynamic impact of laryngoscopy and intubation. Rev Esp Anesthesiol Reanim; 1991;38(4):234-7.

9. Shrestha A, Acharya SP, Amatya R. Comparison of Lignocaine and Esmolol in attenuating cardiovascular response to laryngoscopy and endotracheal intubation; JSAN 2014;1:29-35.

10. Abou-Madi MN, Keszler H, Yacoub JM. Cardiovascular reactions to laryngoscopy and tracheal intubation following small and large intravenous doses of lidocaine. Can Anaesth Soc J 1977;24:12-9.

11. Gupta C et al. Clinical efficacy of Esmolol, Lignocaine and Diltiazem as premedicant for attenuation of hemodynamic responses of laryngoscopy and endotracheal intubation- a comparative evaluation. Int J Res Med Sci. 20170ct;5(10):44434449. www.msjonline.org.

12. Nishina K, Mikawa K, Takao Y, Shiga M, Maekawa N, Obara H.Prostaglandin E1, lidocaine, and prostaglandin E1-lidocaine combination for attenuating cardiovascular responses to extubation. Can J Anaesth. 1997 Nov;44(11):1211-4.

13. Reid LC, Brace DE. Irritation of the respiratory tract and its reflex effect upon heart. Surg Gynaecol Obstet. 1940; 70:157-162.

14. King BD, Harris LC Jr, Greifenstein FE, Elder JD Jr, Dripps RD. Reflex circulatory responses to odirect laryngoscopy and tracheal intubation performed during general anesthesia. Anesthesiology 1951;12:556-566.

15. Fox EJ, Slar CS, Hill CH, Villanueva R, King BD. Complications related to the pressor response to endotracheal intubation. Anesthesiology.1977;47:524-25. 10.1097/00000542197712000-00013.

16. Manpreet Kaur, P. M. Singh. Current role of dexmedetomidine in clinical anesthesia and intensive care. Anesth Essays Res. 2011 Jul-Dec; 5(2):128-133.

17. Prys-Roberts C, Greene LT, Meloche R, Foex P. Studies of anaesthesia in relation to hypertension. II. Haemodynamic consequences of induction and endotracheal intubation. $\mathrm{Br} J$ Anaesth.1971;36:531-547.

18. David Z, Nathaniel R, Kathleen TB et al. Anti angina effects of intravenous nitroglycerin over 24 hours. Circulation.1988 Jul; 77(6):1376-84.

19. Stoelting RK, Hillier SC. Peripheral Vasodilators, Nitric Oxide, and Nitrovasoldilators. Pharmacology and Physiology in Anesthetic Practice. 4th ed. Philadelphia: Lippincott Williams and Wilkins; 2006:361.

20. Catterall WA, Mackie K. Local Anesthetics. In: Brunton L, Chabner B, Knollman B, editors. Goodman and Gilman's The Pharmacological Basis of Therapeutics. 12th ed. New York: McGraw Hill Publishers; 2011. pp. 564-82.

21. Bromage PR, Robson JG. Concentrations of lignocaine in the blood after intravenous, intramuscular epidural and endotracheal administration. Anaesthesia. 1961;16:461-478.

22. Tam S Chung F, Cambell JM. Intravenous Lidocaine: Optimal Time of Injection before Tracheal Intubation. Anaesth analg.1987;66: 1036-8.

23. Kumar N, Batra YK, Bala I et al. Nifedipine attenuates the hypertensive response to tracheal intubation in pregnancy 
induced hypertension. Can J Anesth. 1993;40:329-33.

24. Kim HJ, Jun JH, Yoo HK et al. The effects of remifentanyl, lidocaine, nicardipine and nitroglycerine on hemodynamic changes during tracheal intubation. Korean J Anesthesiol.

25. Padmawar S, Patil M. A Comparative Study of $2 \%$ Lignocaine vs $50 \%$ Magnesium Sulphate for Attenuation of Stress Responses to Laryngoscopy and Endotracheal Intubation.t ljcmr. 2016 Aug; 3(8). 